\title{
Yellow and white diamonds from Qilalugaq kimberlites: Two generations of diamond growth
}

\author{
Anetta Banas ${ }^{1}$, Thomas Stachel ${ }^{2}$, Karen V. Smit ${ }^{3}$, Ken Armstrong ${ }^{4}$ \\ ${ }^{1}$ APEX Geoscience Ltd., Edmonton, Canada, abanas@apexgeoscience.com \\ ${ }^{2}$ University of Alberta, Edmonton, Canada, tstachel@ualberta.ca \\ ${ }^{3}$ Gemological Institute of America, New York, USA, ksmit@gia.edu \\ ${ }^{4}$ North Arrow Minerals Inc., Vancouver, Canada, karmstrong@northarrowminerals.com
}

\section{Introduction}

A population of intense yellow diamonds has been identified at the Q1-4 kimberlite on the Naujaat (formerly the Qilalugaq) Project. The Qilalugaq Kimberlite Field is located near the hamlet of Naujaat (Repulse Bay), Nunavut, Canada. It consists of 16 kimberlites: 8 kimberlite pipes and 8 laterally extensive kimberlite dykes. The kimberlites were emplaced at ca. $546 \mathrm{Ma}$ (Kupsch and Armstrong, 2013). The Q1-4 kimberlite, the largest $(12.5 \mathrm{Ha})$ within the cluster, is interpreted as a multi-phased, complex-shaped kimberlite pipe. An Inferred Mineral Resource of 48.8 million tonnes at a grade of $53.6 \mathrm{cpht}$ (total recovery) containing 26.1 million carats has been reported for Q1-4 (Kupsch and Farrow, 2013).

\section{Background}

In 2014, a bulk sample was collected from the Q1-4 kimberlite to provide additional information on the diamond content of the pipe and to establish whether or not a population of yellow diamonds recovered in earlier sampling persists into the larger diamond sizes. Approximately 384 carats o diamonds larger than $1.1 \mathrm{~mm}(\mathrm{DTC}+1)$ were recovered from the $1,353.3$ tonne bulk sample. The results from the bulk sample confirmed that a population of yellow diamonds is present at Q1-4 and that the yellow diamonds are present into the grainer and carater diamond sizes (North Arrow, 2015a). The yellow diamonds comprise approximately $9.0 \%$ by stone count and $21.5 \%$ by carat weight of the total diamond parcel. The yellow diamonds display a range of hues, tones and saturation levels, ranging from dark/intense (orangy) yellow to very pale yellow (Figure 1). Dark/intense yellow diamonds make up $3.2 \%$ by stone count and $6.5 \%$ by carat weight of the total parcel. The proportion of yellow diamonds increases, both by stone count and carat weight, in the larger size classes (North Arrow, 2015a).

\section{Diamond Samples}

A parcel of rough diamonds containing 56 stones $<1.1 \mathrm{~mm}$ (DTC-1) and 10 stones $\sim 1.8 \mathrm{~mm}$ (DTC +5 ) in size was analysed by FTIR (Fourier Transform Infrared) spectroscopy to determine nitrogen contents and aggregation states. The DTC-1 diamond parcel contained 32 yellow diamonds of varying colour intensity and 24 white diamonds (Figure 1). All 10 DTC +5 diamonds were yellow with varying degrees of colour intensity. Subsequently, an additional 10 diamonds, cut and polished from rough diamonds ranging in size from 0.125 to 4.41 carats, were analysed by FTIR. Nine of the polished diamonds were of saturated orangy yellow colour and one diamond had an intense yellow colour. Four of the polished diamonds were also analysed by VIS-NIR spectroscopy.

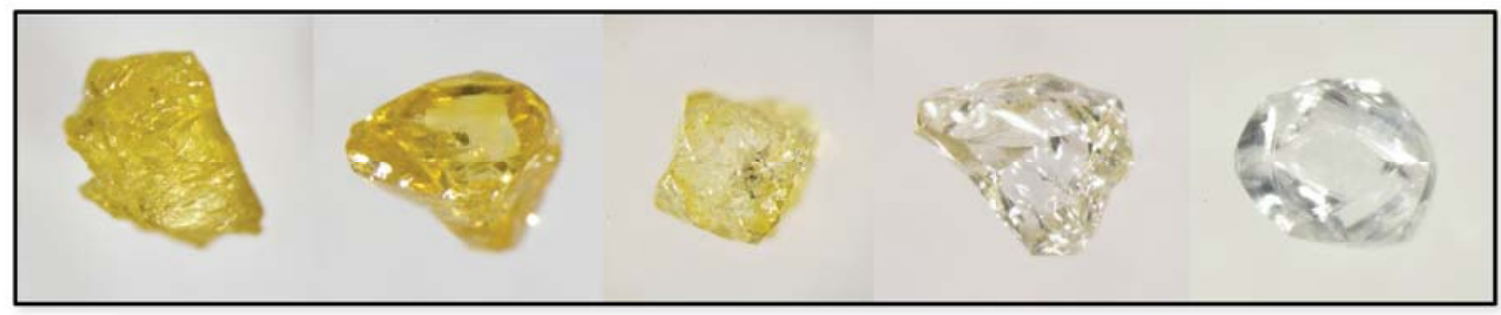

Figure 1. Colour distribution of the DTC-1 diamond parcel. From left to right: green-yellow, intense yellow, pale yellow, very pale yellow and white. 


\section{Results}

The yellow diamonds are largely characterized by cuboid shapes, have a limited range of nitrogen contents between 360 and 748 atomic ppm and contain single substitutional nitrogen (C centres or $\mathrm{Nc}$ ) ranging from $2.9-233$ atomic ppm (Figure 2A). These diamonds are classified as intermediate Type Ib-IaA. VIS-NIR spectroscopy documents a complete absence of N3 centres in four polished yellow diamonds, confirming their Type Ib-IaA classification. Total nitrogen contents and the proportion of nitrogen in $\mathrm{C}$ centres are consistent across the examined size range and consequently, yellow diamonds from all size fractions are considered to be part of one diamond population. C centres cause absorption between 300 and $700 \mathrm{~nm}$ in the visible light range, resulting in yellow colours that are often described as "canary" or saturated yellow in the gem trade. For this sample set a broad correlation exists between the concentration of nitrogen in the C-centre and the intensity of the yellow colour where a higher Nc concentration results in a more vivid yellow to orangy yellow colour.
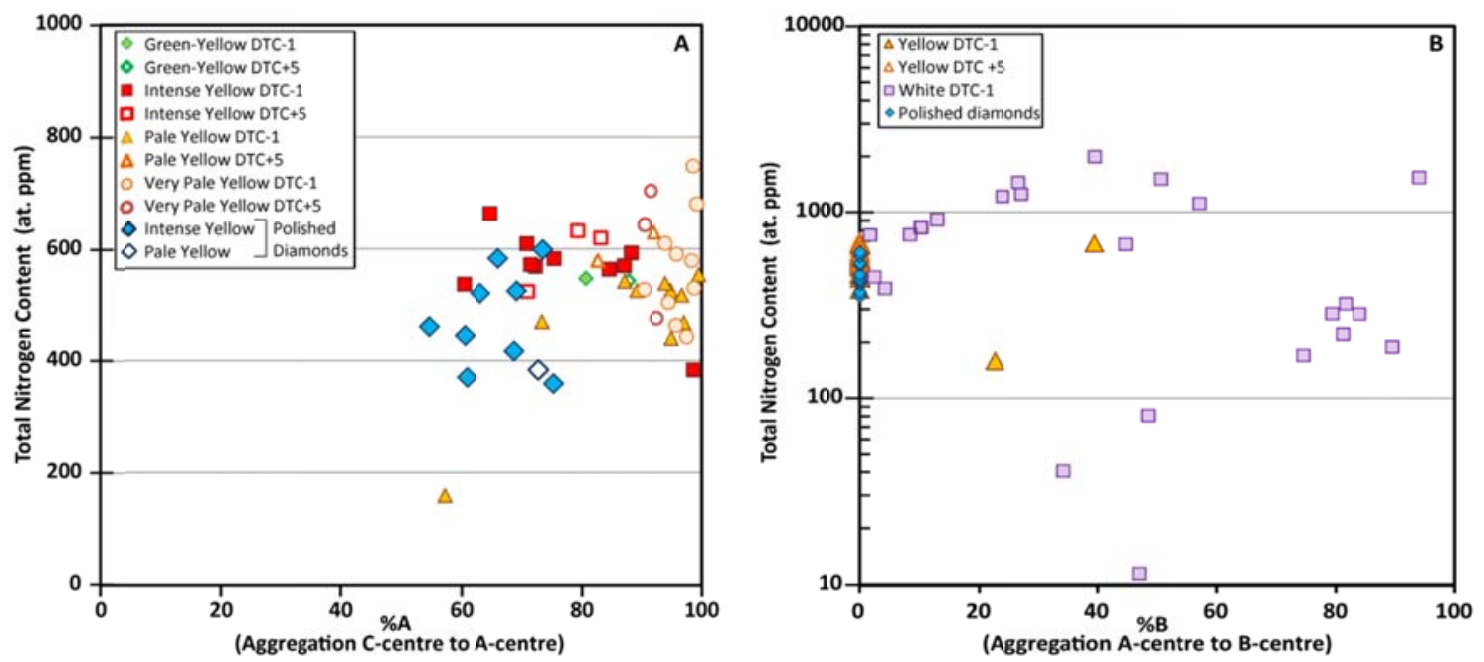

Figure 2. Nitrogen aggregation charcteristics for diamonds from Q1-4: A) \%A (100* A/(A+C)) aggregation vs total nitrogen content (atomic ppm) for Type Ib-IaA yellow diamonds and $\mathbf{B}) \% \mathrm{~B}(100 * \mathrm{~A} /(\mathrm{A}+\mathrm{B}))$ aggregation vs total nitrogen content (atomic ppm) for all diamonds.

The white (colourless) diamonds are mainly characterized by octahedral and dodecahedral (resorbed octahedral) shapes. They have a broad range in total nitrogen contents ranging from $11-1994$ atomic $\mathrm{ppm}$. The white diamonds can be classified as Type IaAB based on the presence of fully aggregated nitrogen in B-centres ranging from 2-94\%B (Figure $2 \mathrm{~B}$ ).

\section{Implications for Diamond Formation}

The relative concentration of A-centres in Type Ib-IaA diamonds and the relative concentration of Bcentres in IaAB diamonds can be used to provide constraints on the mantle residence time or the timeaveraged residence temperature of the diamonds if one or the other is known (Taylor et al., 1996; Leahy and Taylor 1997). Since no constraints on residence time are available (i.e. no diamond ages) for the Qilalugaq area a temperature constraint based on the geotherm was used to estimate mantle residence times for the diamonds. A $38-40 \mathrm{~mW} / \mathrm{m}^{2}$ geotherm has been modelled based on clinopyroxene from garnet peridotite (Kupsch and Armstrong, 2013).

For the yellow diamonds the modelling indicates possible mantle residence times in the range of thousands of years up to a few 10's of millions of years. The maximum modelled mantle residence time for the Type Ib-IaA diamonds is $30 \mathrm{Ma}$.

Given that a typical cratonic geotherm has been calculated for the Qilalugaq area, the temperature distribution of the Q1-4 Type IaAB diamonds should approximately correspond to that of cratonic 
diamonds worldwide. Worldwide cratonic diamonds have a $\mathrm{T}_{\text {Nitrogen }}$ (temperature calculated from nitrogen aggregation) distribution of $1150 \pm 70^{\circ} \mathrm{C}$ (Stachel, 2014). Applying the maximum $30 \mathrm{Ma}$ mantle residence time caculated for the Type Ib-IaA diamonds to the Type IaAB diamonds gives a $\mathrm{T}_{\text {Nitrogen }}$ distribution of $1240 \pm 70^{\circ} \mathrm{C}$. This would indicate mantle storage under exceptionally hot conditions. For a $1 \mathrm{Ga}$ mantle residence time, Q1-4 Type IaAB diamonds have a $\mathrm{T}_{\mathrm{N}}$ distribution of $1150 \pm 60^{\circ} \mathrm{C}$, in perfect accordance with the worlwide distribution indicating that the white diamonds represent an older generation of diamond formation in the Qilalugaq area.

\section{Conclusions}

The majority ( $\sim 98 \%$ ) of diamonds worldwide are classified as Type Ia and range between IaA and IaB. Natural Type Ib diamonds are exceptionally rare, estimated to make up less than $0.1 \%$ of natural diamonds globally (Harlow, 1998). The studied yellow diamonds from the Q1-4 contain unaggregated nitrogen, a defining charateristic of natural Type Ib diamonds with the highly coveted canary yellow color. The high proportion of Type Ib diamonds recovered from Q1-4 is extremely unusual (North Arrow, 2015b).

Based on the spectroscopic data, the yellow and white diamonds from Q1-4 are interpreted as two discrete populations. The lack of overlap in the mantle residence time estimates for yellow and white Qilalugaq diamonds implies that these two populations were formed during temporally distinct diamond forming events. The white diamonds share the nitrogen characteristics of typically Archean to Paleoproterozoic diamond populations worldwide. In contrast, the yellow diamonds likely formed in temporal proximity to host kimberlite magmatism. Fancy yellow colors can have a positive impact on diamond valuation; therefore, understanding the characteristics and distribution of the yellow diamond population is critical to further the evaluation of the economic potential of the Q1-4 kimberlite.

\section{References}

Harlow, G. E. (1998) The Nature of Diamonds. American Museum of Natural History. 278p.

Kupsch, B., Armstrong. J. (2013) Exploration and Geology of the Qilalugaq Kimberlites, Rae Isthmus, Nunavut, Canada. In: D.G. Pearson et al (eds.) Proceedings of the $10^{\text {th }}$ International Kimberlite Conference Volume 2, Special Issue of the Journal of the Geological Society of India, P. 67-78.

Kupsch, B., Farrow, D. (2013) Qilalugaq Diamond Project Nunavut, Canada, NI 43-101 Technical Report Mineral Resource. Prepared for North Arrow Minerals Inc. www.Sedar.com 73p.

Leahy, K., Taylor, W.R., (1997) The influence of the Glennie domain deep structure on the diamonds in Saskatchewan kimberlites. Russian Geology and Geophysics 38 (2), 481-491.

North Arrow Minerals Inc. (2015a) North Arrow Reports Final Diamond Recoveries From the Qilalugaq Bulk Sample. Press Release May 5, 2015. www.Sedar.com 2p.

North Arrow Minerals Inc. (2015b) North Arrow Reports Yellow Diamonds From Q1-4 Kimberlite are Rare Natural Type Ib Diamonds Press Release April 21, 2015. www.Sedar.com 2p.

Stachel, T. (2014) Diamonds. In: Groat, L. (ed) Geology of Gem Deposists Edition 2, Mineralogical Association of Canda Short Course, V44, 1-28.

Taylor, W.R., Canil, D., Milledge, H.J. (1996) Kinetics of Ib to IaA nitrogen aggregation in diamond. Geochim. Cosmochim. Acta 60, 4725-4733. 